\title{
APLIKASI PENGINDERAAN JAUH DAN SIG DENGAN METODE ANALYTICAL HIERARCHY PROCESS UNTUK KAJIAN KERAWANAN BANJIR DI DAS JALI COKROYASAN PURWOREJO
}

\author{
Bayu Aji Sidiq Pramono ${ }^{1}$, Karunia Pasya Kusumawardani, Emy Puspita Yuendini', \\ Sudaryatno ${ }^{I}$ \\ ${ }^{I}$ Departemen Sains Informasi Geografi, Fakultas Geografi, Universitas Gadjah Mada, Yogyakarta \\ ${ }^{2}$ Departemen Geografi Lingkungan, Fakultas Geografi, Universitas Gadjah Mada, Yogyakarta
}

\begin{abstract}
ABSTRAK
Bencana hidrometeorologi adalah bencana yang dipengaruhi oleh parameter meteorologi yang meliputi aspek cuaca seperti curah hujan, angin, suhu, dan kelembaban. Salah satu bencana hidrometeorologi yang terjadi di Indonesia yaitu banjir. Dalam 8 tahun terakhir, telah terjadi banjir di DAS Jali Cokroyasan yang menggenangi sebagian Kabupaten Purworejo. Penelitian dilakukan untuk mengetahui tingkat kerawanan banjir di DAS Jali Cokroyasan. Penggunaan teknologi penginderaan jauh dan Sistem Informasi Geografi (SIG) diaplikasikan untuk memetakan tingkat kerawanan banjir di DAS Jali Cokroyasan. Parameter yang digunakan antara lain curah hujan, penggunaan lahan, kemiringan lereng, dan bentuklahan. Data curah hujan didapatkan dari Dinas Pertanian Peternakan Kelautan dan Perikanan Kabupaten Purworejo. Data penggunaan lahan didapatkan dari citra Landsat 8 OLI yang diolah berdasarkan klasifikasi multispektral tidak terselia. Data kemiringan lereng diekstraksi dari DEM ALOS PALSAR dengan resolusi $10 \mathrm{~m}$. Data bentuklahan dihasilkan dari interpretasi visual DEM ALOS PALSAR dan citra Landsat 8 OLI. Semua parameter diproses dengan analisis spasial berdasarkan metode skoring Analytical Hierarchy Process $(A H P)$ dan metode overlay Spatial Multi Criteria Evaluation (SMCE). Pengujian model dilakukan dengan metode in depth interview. Hasil analisis berupa peta tingkat kerawanan banjir di DAS Jali Cokroyasan. Berdasarkan peta tersebut, hilir DAS yang mendekati outlet DAS menjadi area yang rawan terjadinya bencana banjir luapan karena hilir DAS memiliki topografi yang landai. Zonasi tingkat kerawanan pada peta diharapkan menjadi bahan pertimbangan dalam menanggulangi resiko akibat banjir, meningkatkan kapasitas masyarakat, dan meminimalisasi kerugian akibat bencana.
\end{abstract}

Kata kunci: banjir, DAS Jali Cokroyasan, penginderaan jauh, SIG, kerawanan

\begin{abstract}
Hydrometeorological disaster is a disaster that is affected by meteorological parameters covering weather aspects such as rainfall, wind, temperature, and humidity. One of the hydrometeorological disasters occurring in Indonesia is flooding. In the last 8 years, there have been floods in the Jali Cokroyasan watershed that flooded some Purworejo regency. This research was conducted to determine the level of flood suseptibilty in Jali Cokroyasan watershed. The use of remote sensing technology and Geographic Information System (GIS) was applied to mapping the level of flood suseptibilty in Jali Cokroyasan watershed. Parameters used include rainfall, land use, slope, and landform. Rainfall data obtained from the Department of Agriculture Husbandry Marine and Fisheries Purworejo District. Land use data were obtained from Landsat 8 OLI image then processed based on unsupervised multispectral classification. The slope slope data is extracted from DEM ALOS PALSAR with $10 \mathrm{~m}$ resolution. Landform data is generated from visual interpretations of DEM ALOS PALSAR and Landsat 8 OLI image. All parameters are processed by spatial analysis based on the Analytical Hierarchy Process (AHP) skoring method and Spatial Multi Criteria Evaluation (SMCE) overlay method. Model testing is conducted with the method of in depth interview. The results of the analysis is the map of flood suseptibility in Jali Cokroyasan watershed. Based on the map, downstream watershed approaching watershed outlets become areas prone to flood disaster because downstream downstream has a sloping topography. Zoning of vulnerability on the map is expected to be considered in tackling flood risks, increasing community capacity, and minimizing disaster losses.
\end{abstract}

Keywords: flood, Jali Cokroyasan Watershed, remote sensing. GIS, suseptibility 


\section{PENDAHULUAN}

Kabupaten Purworejo secara geografis terdiri atas tiga cakupan wilayah Daerah Aliran Sungai (DAS), salah satunya DAS Jali Cokroyasan. DAS tersebut merupakan wilayah aliran sungai yang memiliki hulu di Kabupaten Wonosobo yang berbatasan dengan Pegunungan Kendeng dan hilir di Kabupaten Purworejo dengan muara di Samudera Hindia. DAS Jali Cokroyasan memiliki luas $405.500 \mathrm{~km}^{2}$ dengan sungai utama yaitu Sungai Jali yang diapit oleh dua DAS besar lainnya. Batas sisi barat adalah DAS Wawar sedangkan di sisi timur berbatasan dengan DAS Bogowonto.

Kondisi geografis Kabupaten Purworejo yang berada di daerah aliran sungai besar menyebabkan sebagian Kabupaten Purworejo rawan akan bencana hidrometeorologi salah satunya banjir. Selama 10 tahun terakhir, banjir terjadi di sebagian DAS di Kabupaten Purworejo. Kejadian banjir di DAS Jali Cokroyasan terjadi sejak tahun 2011 hingga tahun 2017. Menurut Heksantoro (2017), banjir pernah terjadi di Kecamatan Grabag karena luapan anak sungai Jali yaitu Sungai Lereng yang dipicu oleh curah hujan tinggi. Banjir luapan juga pernah terjadi di sebagian Kecamatan Ngombol dan Kecamatan Purwodadi pada tahun 2011.

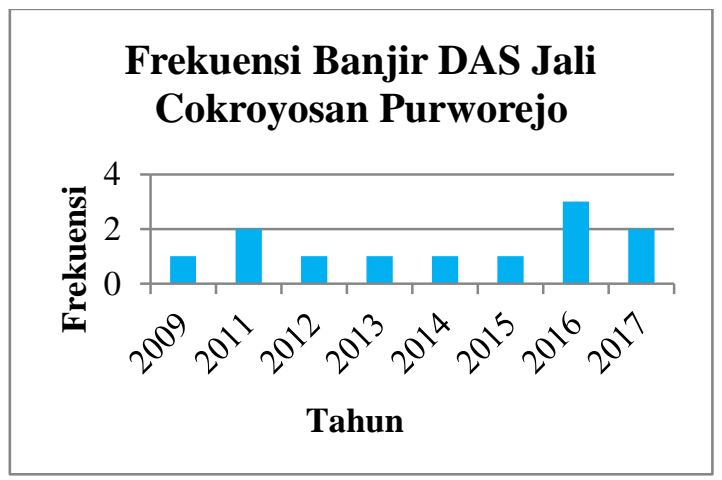

Grafik 1. Frekuensi Banjir DAS Jali Cokroyasan Purworejo

Kejadian banjir luapan yang sering terjadi DAS Jali Cokroyasan Purworejo menyebabkan wilayah di sekitar sungai menjadi rawan sehingga resiko bencana akan meningkat. Atas dasar hal tersebut dibutuhkan kajian kerawanan banjir di DAS Jali Cokroyasan Purworejo. Tulisan ini menjelaskan tingkat kerawanan banjir di DAS Jali Cokroyasan Purworejo. Penggunaan citra satelit penginderaan jauh digunakan karena dapat menggambarkan wilayah DAS yang luas dan memiliki resolusi temporal tinggi. Citra penginderaan jauh juga dapat dianalisis lebih lanjut dan disajikan dalam bentuk peta melalui teknologi Sistem Informasi Geografis. Teknologi SIG dapat mengolah data spasial atau citra yang tergeoreferensi geografis seperti yang dipaparkan Aronof (1989) bahwa SIG merupakan suatu sistem yang berbasis komputer yang digunakan untuk mengolah dan menyimpan data yang bereferensi geografis. Teknologi SIG dalam kajian ini digunakan untuk menganalisis parameter dan menyajikan informasi kerawanan banjir di DAS Jali Cokroyasan Purworejo.

\section{METODE PENELITIAN}

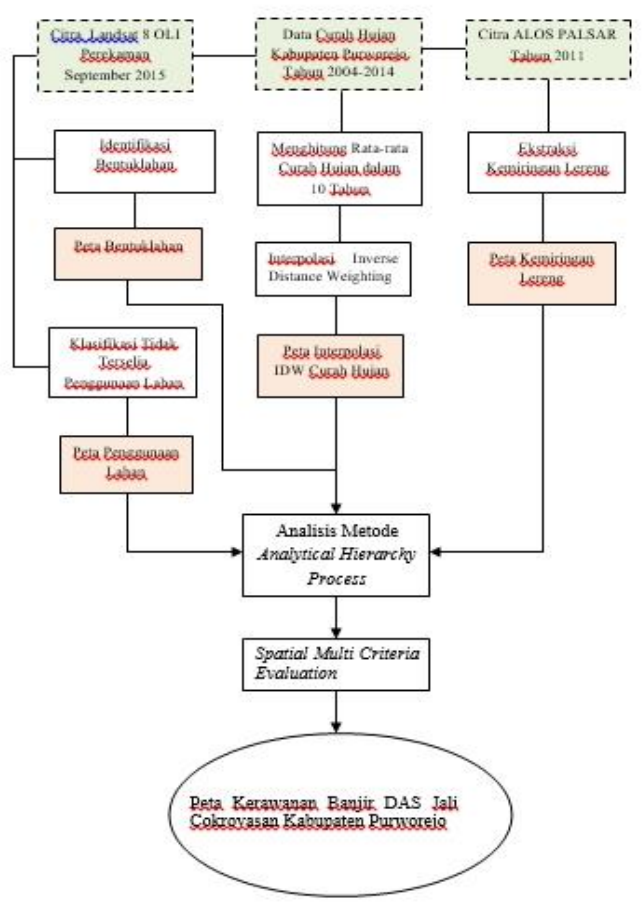

Gambar 1. Diagram Alir

2.1 Pra Lapangan

a. Pembuatan Peta Penggunaan Lahan DAS Jali Cokroyasan Kabupaten Purworejo Tahun 2015

Penggunaan lahan merupakan fungsi lahan dengan segala campur tangan manusia baik secara permanen maupun secara siklus terhadap suatu kelompok sumberdaya alam dan sumberdaya buatan dengan tujuan untuk memenuhi kebutuhan manusia (Malingreau, 1977). Penggunaan lahan menjadi sangat penting terhadap banyak bentuk pemetaan tematik karena pengaruh timbal baliknya secara langsung terhadap kehidupan manusia. Variasi dan perubahan yang relatif cepat menjadikan 
penggunaan lahan menjadi parameter yang patut selalu diperhatikan.

Peta penggunaan lahan dibuat dengan menggunakan citra penginderaan jauh Landsat 8 OLI path 120 row 65 dengan tanggal perekaman 18 September 2015. Pemilihan waktu perekaman didasarkan pada bulan basah dan integrasi dengan data lain. Asumsi yang dibangun adalah bahwa dalam bulan basah daerah kajian memiliki input air hujan dalam keadaan mendekati maksimum. Citra tersebut diproses dengan melakukan klasifikasi multispektral terselia dengan membangun lima kelas penggunaan lahan berdasarkan klasifikasi SNI 7645-2010 mengenai klasifikasi penutup lahan skala 1:100.000.

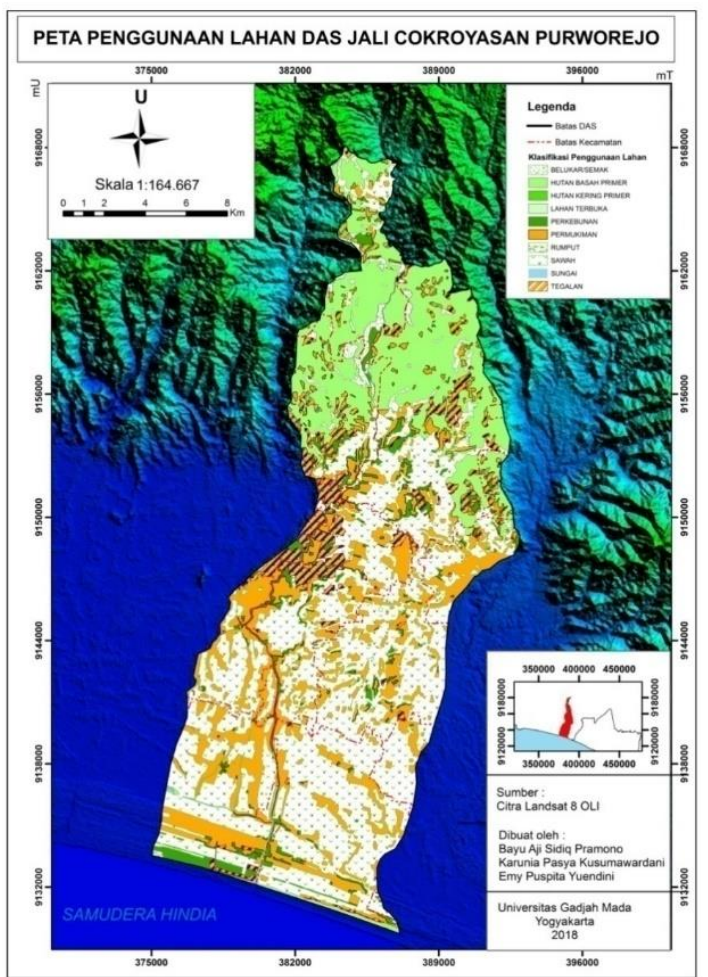

Gambar 2. Peta Penggunaan Lahan DAS Jali Cokroyasan

b. Pembuatan Peta Bentuklahan DAS Jali Cokroyasan Kabupaten Purworejo Tahun 2015

Peta bentuklahan dibuat dengan menggunakan citra penginderaan jauh Landsat 8 OLI seperti yang digunakan untuk pembuatan peta penggunaan lahan dan DEM ALOS Palsar dengan resolusi 10 meter. Klasifikasi bentuklahan yang digunakan adalah menurut Prapto Suharsono (1999) dengan skala 1:100.000.

Proses klasifikasi dilakukan dengan cara interpretasi visual pada perangkat lunak ArcMap dengan pendekatan unsur - unsur interpretasi menurut Liliesand dan Kiefer (1990). Klasifikasi yang diperoleh selanjutnya akan digunakan untuk mengestimasi tekstur relatif tanah sebagai indikasi kapasitas infiltrasi setiap satuan lahan.

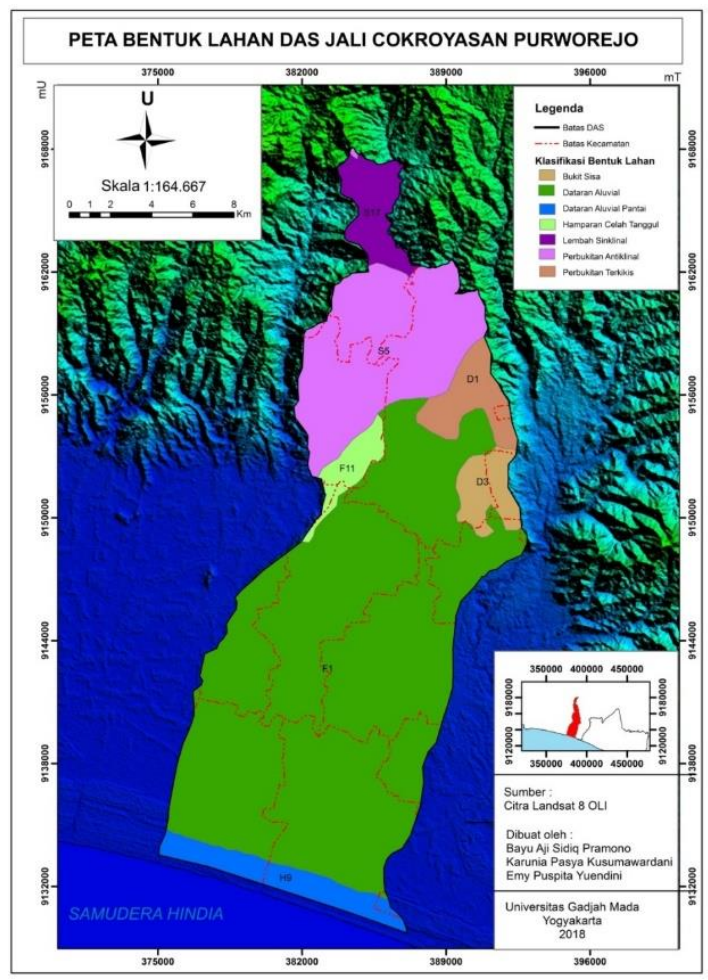

Gambar 3. Peta Bentuklahan DAS Jali Cokroyasan Kabupaten Purworejo

\section{c. Pembuatan Peta Curah Hujan DAS Jali Cokroyasan Kabupaten Purworejo}

Data curah hujan tahun 2004-2014 didapatkan dari Dinas Pertanian Peternakan Kelautan dan Perikanan Kabupaten Purworejo. Data multitemporal curah hujan selama 10 tahun tersebut digunakan karena fenomena banjir yang terjadi di DAS Jali Cokroyasan Purworejo tidak hanya pada satu tahun tertentu saja melainkan fenomena yang memiliki periode ulang mulai dari tahun 2009 hingga 2017. Data curah hujan yang didapatkan merupakan data curah hujan tiap kecamatan di Kabupaten Purworejo sehingga data yang digunakan hanya wilayah kecamatan yang berada dalam daerah aliran sungai saja.

Data curah hujan dari sumber merupakan data curah hujan bulanan dalam setahun kemudian dilakukan pengolahan data tersebut menjadi intensitas hujan rata-rata tahunan mulai dari tahun 2004-2014. Selanjutnya dilakukan interpolasi data curah hujan menggunakan metode Inverse Distance Weighting (IDW). Metode tersebut digunakan karena 
memperhitungkan jarak sebagai bobot sehingga jarak terdekat akan memiliki bobot yang lebih tinggi seperti yang dipaparkan oleh $\mathrm{Lu}$ dan Wong (2008) bahwa nilai atribut dari titik yang tidak diketahui nilainya dalah rata-rata tertimbang nilai yang diketahui pada titik disekitarnya yang diketahui dan bobotnya berbanding terbalik dengan jarak antara lokasi estimasi dan lokasi yang sudah diketahui nilainya. Berdasarkan adanya pembobotan, wilayah dalam satu kecamatan akan memiliki intensitas hujan yang sama karena berdekatan dan intensitas hujan wilayah sekitarnya dapat diestimasi.

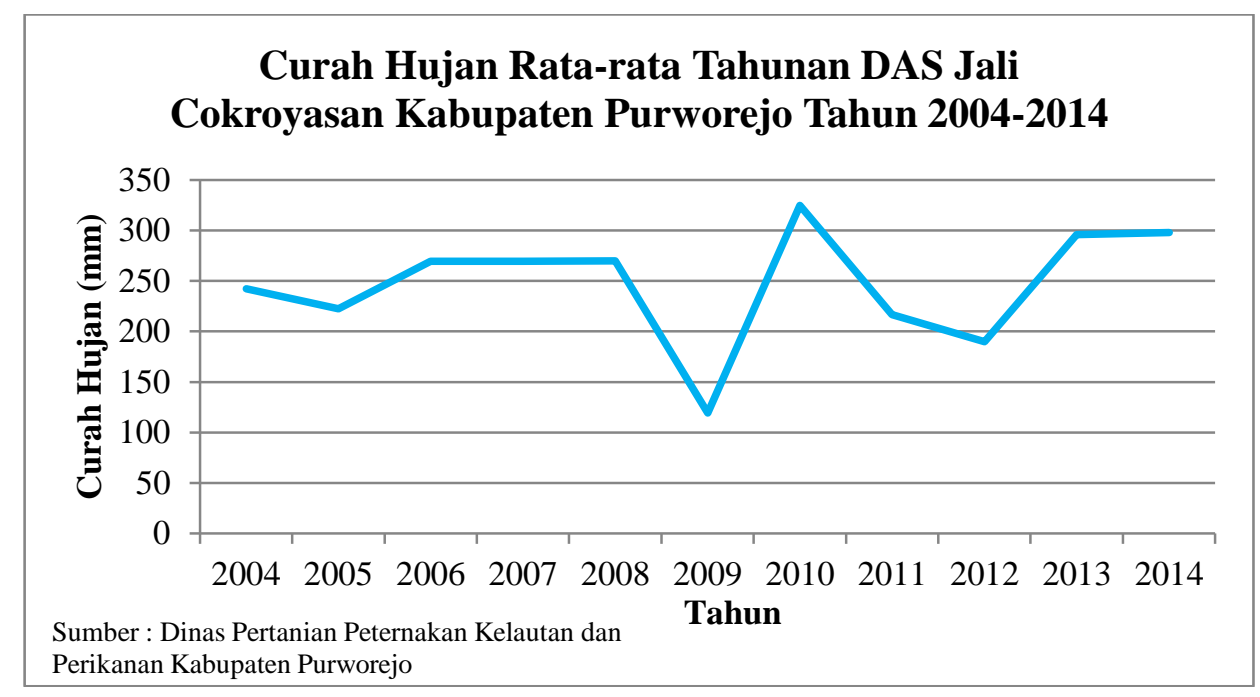

Grafik 2. Curah Hujan Rata-rata Tahunan DAS Jali Cokroyasan Purworejo

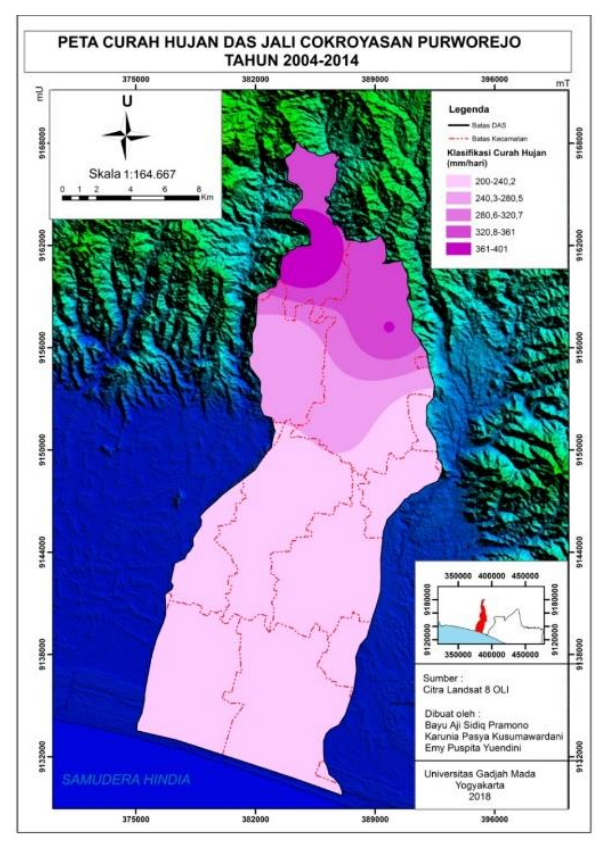

Gambar 4. Peta Curah Hujan DAS Jali Cokroyasan

d. Pembuatan Peta Kemiringan Lereng DAS Jali Cokroyasan Kabupaten Purworejo

Peta kemiringan lereng dibuat melalui ekstraksi dari DEM ALOS Palsar dengan resolusi 30 meter. DEM ALOS PALSAR menggunakan gelombang $\mathrm{L}$ yang memiliki tingkat penetrasi yang tinggi terhadap tutupan vegetasi. Sehingga mampu untuk menghasilkan DEM yang mencapai permukaan. Namun untuk lahan yang memiliki kerapatan vegetasi cukup tinggi, gelombang yang dipancarkan oleh DEM ALOS PALSAR tidak mampu untuk mencapai permukaan. Sehingga DEM produk dari ALOS 
PALSAR cenderung semi DSM (Digital Surface Model).

Peta kemiringan lereng dibuat dengan skala 1:200.000. Kemiringan lereng sangat berkaitan dengan tingkat kerawanan banjir. Klasifikasi kemiringan lereng dilakukan dalam satuan derajat. Hal tersebut disebabkan karena satuan tersebut lebih lumrah dan banyak digunakan.

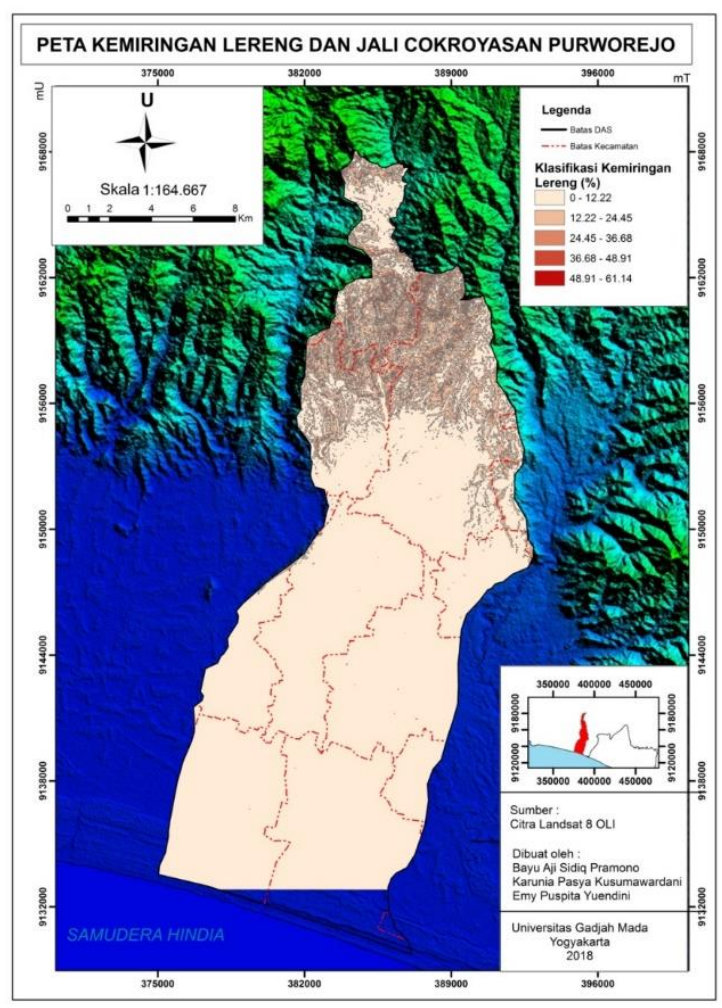

Gambar 5. Peta Kemiringan Lereng DAS Jali Cokroyasan e. Pembuatan Peta Kerawanan Banjir DAS Jali Cokroyasan Kabupaten Purworejo

Peta kerawanan banjir dibuat dengan menggunakan metode Analytical Hierarchy Process dan Spatial Multi-Criteria Evaluation dengan menggunakan perangkat lunak ILWIS 3.3. Parameter yang digunakan yaitu kemiringan lereng, curah hujan, bentuklahan, dan penggunaan lahan. Parameter tersebut merupakan aspek-aspek yang dianggap berpengaruh besar terhadap kerawanan banjir. Analytical Hierarchy Process merupakan salah satu metode pembobotan yang bersifat sangat rinci, sistematis, dan matematis yang digunakan untuk memecahkan masalah yang kompleks dengan menyusun hirarki pembobotan mulai dari sub-parameter secara terstruktur (Rai dan Bushan, 2004). Setiap sub-parameter diperhitungkan tingkat hubungan dan pengaruhnya terhadap kerawanan banjir. Parameter yang digunakan juga dibobot dengan metode yang sama untuk menentukan parameter yang dianggap paling berpengaruh terhadap kerawanan banjir. 


\begin{tabular}{|c|c|c|c|c|c|c|c|c|c|c|}
\hline Bentuklahan & $\begin{array}{l}\text { Dataran } \\
\text { Aluvial }\end{array}$ & $\begin{array}{l}\text { Dataran } \\
\text { Aluvial Pantai }\end{array}$ & $\begin{array}{l}\text { Lembah } \\
\text { Sinklinal }\end{array}$ & \begin{tabular}{|l} 
Perbukitan \\
Terkikis
\end{tabular} & $\begin{array}{l}\text { Lereng Gunung } \\
\text { Api }\end{array}$ & \begin{tabular}{|l} 
Bukit \\
Sisa
\end{tabular} & \begin{tabular}{|l} 
Hamparan \\
Celah Tanggul
\end{tabular} & $\begin{array}{l}\text { Kaki Gunung } \\
\text { Api }\end{array}$ & $\begin{array}{l}\text { Beting } \\
\text { Gisik }\end{array}$ & $\begin{array}{l}\text { Perbukitan } \\
\text { Antiklinal }\end{array}$ \\
\hline $\begin{array}{l}\text { Dataran } \\
\text { Aluvial }\end{array}$ & & 3.00 & 2.00 & 5.00 & 5.00 & 7.00 & 5.00 & 5.00 & 3.00 & 7.00 \\
\hline $\begin{array}{l}\text { Dataran } \\
\text { Aluvial Pantai }\end{array}$ & 0.33 & & 1.00 & 1.00 & 2.00 & 2.00 & 2.00 & 3.00 & 3.00 & 4.00 \\
\hline $\begin{array}{l}\text { Lembah } \\
\text { Sinklinal }\end{array}$ & 0.50 & 1.00 & & 1.00 & 1.00 & 2.00 & 2.00 & 2.00 & 3.00 & 3.00 \\
\hline $\begin{array}{l}\text { Perbukitan } \\
\text { Terkikis }\end{array}$ & 0.20 & 1.00 & 1.00 & & 1.00 & 1.00 & 2.00 & 2.00 & 2.00 & 3.00 \\
\hline $\begin{array}{l}\text { Lereng } \\
\text { Gunung Api }\end{array}$ & 0.20 & 0.50 & 1.00 & 1.00 & & 1.00 & 1.00 & 2.00 & 2.00 & 2.00 \\
\hline Bukit Sisa & 0.14 & 0.50 & 0.50 & 1.00 & 1.00 & & 1.00 & 1.00 & 2.00 & 2.00 \\
\hline $\begin{array}{l}\text { Hamparan } \\
\text { Celah } \\
\text { Tanggul }\end{array}$ & 0.20 & 0.50 & 0.50 & 0.50 & 1.00 & 1.00 & & 1.00 & 1.00 & 2.00 \\
\hline $\begin{array}{l}\text { Kaki Gunung } \\
\text { Api }\end{array}$ & 0.20 & 0.33 & 0.50 & 0.50 & 0.50 & 1.00 & 1.00 & & 1.00 & 1.00 \\
\hline Beting Gisik & 0.33 & 0.33 & 0.33 & 0.50 & 0.50 & 0.50 & 1.00 & 1.00 & & 1.00 \\
\hline $\begin{array}{l}\text { Perbukitan } \\
\text { Antiklinal }\end{array}$ & 0.14 & 0.25 & 0.33 & 0.33 & 0.50 & 0.50 & 0.50 & 1.00 & 1.00 & \\
\hline
\end{tabular}

Gambar 6. Matriks Analytical Hierarchy Process untuk parameter bentuklahan

\begin{tabular}{|c|c|c|c|c|c|c|c|c|c|c|}
\hline $\begin{array}{l}\text { Penggunaan } \\
\text { Lahan }\end{array}$ & Sungai & Belukar & $\begin{array}{l}\text { Hutan Basah } \\
\text { Primer } \\
\end{array}$ & $\begin{array}{l}\text { Hutan Kering } \\
\text { Primer } \\
\end{array}$ & $\begin{array}{l}\text { Lahan } \\
\text { Terbuka }\end{array}$ & Perkebunan & Permukiman & Rumput & Sawah & Tegalan \\
\hline Sungai & & 5.00 & 7.00 & 7.00 & 3.00 & 3.00 & 2.00 & 2.00 & 2.00 & 3.00 \\
\hline Belukar & 0.20 & & 1.00 & 1.00 & 2.00 & 2.00 & 2.00 & 3.00 & 3.00 & 4.00 \\
\hline $\begin{array}{l}\text { Hutan Basah } \\
\text { Primer }\end{array}$ & 0.14 & 1.00 & & 1.00 & 1.00 & 2.00 & 2.00 & 2.00 & 3.00 & 3.00 \\
\hline $\begin{array}{l}\text { Hutan Kering } \\
\text { Primer }\end{array}$ & 0.14 & 1.00 & 1.00 & & 1.00 & 1.00 & 2.00 & 2.00 & 2.00 & 3.00 \\
\hline $\begin{array}{l}\text { Lahan } \\
\text { Terbuka }\end{array}$ & 0.33 & 0.50 & 1.00 & 1.00 & & 1.00 & 1.00 & 2.00 & 2.00 & 2.00 \\
\hline Perkebunan & 0.33 & 0.50 & 0.50 & 1.00 & 1.00 & & 1.00 & 1.00 & 2.00 & 2.00 \\
\hline Permukiman & 0.50 & 0.50 & 0.50 & 0.50 & 1.00 & 1.00 & & 1.00 & 1.00 & 2.00 \\
\hline Rumput & 0.50 & 0.33 & 0.50 & 0.50 & 0.50 & 1.00 & 1.00 & & 1.00 & 1.00 \\
\hline Sawah & 0.50 & 0.33 & 0.33 & 0.50 & 0.50 & 0.50 & 1.00 & 1.00 & & 1.00 \\
\hline Tegalan & 0.33 & 0.25 & 0.33 & 0.33 & 0.50 & 0.50 & 0.50 & 1.00 & 1.00 & \\
\hline $\begin{array}{l}\text { Jumlah } \\
\text { kolom }\end{array}$ & 3.99 & 10.42 & 17 & 13.83 & 11.50 & 13.00 & 3.50 & 16.00 & 18.00 & 22.00 \\
\hline
\end{tabular}

Gambar 7. Matriks Analytical Hierarchy Process untuk Parameter Penggunaan Lahan

\begin{tabular}{l|l|l|r|r|c}
\hline Kemiringan Lereng & \multicolumn{1}{|l|}{$0-12.2$} & \multicolumn{1}{|l}{$12.2-24.4$} & $24.4-36.7$ & $36.7-48.9$ & $48.9-61.1$ \\
\hline $0-12.2$ & & 2.00 & 3.00 & 4.00 & 5.00 \\
\hline $12.2-24.4$ & 0.50 & & 0.50 & 0.33 & 2.00 \\
\hline $24.4-36.7$ & 0.33 & 2.00 & & 0.50 & 2.00 \\
\hline $36.7-48.9$ & 0.25 & 3.00 & 2.00 & & 3.00 \\
\hline $48.9-61.1$ & 0.20 & 0.50 & 0.50 & 0.33 & \\
\hline
\end{tabular}

Gambar 8. Matriks Analytical Hierarchy Process untuk Parameter Kemiringan Lereng

\begin{tabular}{|l|c|c|c|r|r}
\hline Curah Hujan & $360.8-401$ & $320.6-360.8$ & $280.4-320.6$ & $240.2-280.4$ & $200-240.2$ \\
\hline $360.8-401$ & & 1.50 & 3.00 & 4.00 & 5.00 \\
\hline $320.6-360.8$ & 0.67 & & 0.50 & 0.33 & 2.00 \\
\hline $280.4-320.6$ & 0.33 & 2.00 & & 0.50 & 2.00 \\
\hline $240.2-280.4$ & 0.25 & 3.00 & 2.00 & & 3.00 \\
\hline $200-240.2$ & 0.20 & 0.50 & 0.50 & 0.33 & \\
\hline
\end{tabular}

Gambar 9. Matriks Analytical Hierarchy Process untuk Parameter Curah Hujan

\begin{tabular}{|l|c|c|c|c|}
\hline Kerawanan & Slope & Curah Hujan & Bentuk Lahan & Penggunaan Lahan \\
\hline Slope & & 2.00 & 1.50 & 3.00 \\
\hline Curah Hujan & 0.50 & & 0.50 & 0.33 \\
\hline Bentuk Lahan & 0.67 & 2.00 & & 0.50 \\
\hline Penggunaan Lahan & 0.33 & 3.00 & 2.00 & \\
\hline
\end{tabular}

Gambar 10. Matriks Analytical Hierarchy Process untuk Parameter Kerawanan Banjir

Spatial Multi-Criteria Evaluation(SMCE) merupakan salah satu dari Spatial Decision
Support System (SDSS). SDSS merupakan salah satu cara dalam menentukan langakah 
atau keputusan berbasis spasial. SDSS sebenarnya sering digunakan dalam memnentukan keputusan sederhana, seperti menentukan arah jalan, rute tercepat menuju suatu tempat, dan sebagainya (Jankowski dkk, 2009). SMCE termasuk dalam perspective tool Spatial Decision Support System. Perspektif tersebut merujuk pada berbagai alat yang digunakan untuk membuat keputusan terkait aspek spasial. Alat tersebut dapat berbasis Sistem Informasi Geografis atau berbasis citra penginderaan jauh. Tujuan dari perspektif tersebut adalah untuk mendapatkan informasi dari data spasial yang rumit menjadi lebih sederhana sehingga dapat digunakan untuk mengambil keputusan

\subsection{Lapangan}

a. Uji Akurasi Peta Parameter

Peta parameter yang telah dibuat melalui ekstraksi dari data penginderaan jauh tentu perlu untuk diuji tingkat akurasinya. Hal tersebut disebabkan karena data penginderaan jauh memiliki beberapa kelemahan dalam beberapa kondisi. Pengujian peta juga berguna untuk tingkat kepercayaan penggunaan peta. Semakin tinggi tingkat akurasinya maka peta tersebut semakin terpercaya untuk dapat digunakan untuk kepentingan berikutnya.

Uji akurasi dilakukan dengan menggunakan metode sampling dengan skema stratified random sampling. Sampel yang dibuat berjumlah 30 sampel yang terdistribusi merata untuk setiap kelas. Sampel yang telah diuji dilapangan selanjutnya akan dianalisis secara statistik untuk melihat tingkat hubungan setiap parameter. Analisis statistik dilakukan dengan melakukan analisis regresi dan korelasi.

\section{b. Uji Model Peta Kerawanan Banjir DAS Jali Cokroyasan Kabupaten Purworejo}

Peta kerawanan banjir diuji dengan menggunakan in depth interview pada sampelsampel uji yang sama dengan sampel uji peta parameter. Proses in depth interview dilakukan pada narasumber yang dianggap sangat memahami terkait kejadian banjir atau DAS Jali Cokroyasan. Hasil dari uji model melalui pendekatan in depth interview akan digunakan untuk menentukan akurasi secara kualitatif peta kerawanan banjir.

\subsection{Pasca Lapangan}

a. Reklasifikasi Peta Penggunaan Lahan Reklasifikasi peta dilakukan pada parameterparameter yang dapat diuji di lapangan. Yaitu parameter penggunaan lahan, dan kemiringan lereng. Reklasifikasi bertujuan untuk meningkatkan relevansi kebenaran antara peta parameter dengan kaadaan sesungguhnya di lapangan. Parameter bentuklahan dan curah hujan tidak diuji dan tidak direklasifikasi dengan asumsi bahwa bentuklahan dan curah hujan merupakan parameter yang tidak mudah berubah dalam jangka waktu yang singkat. Sedangkan penggunaan lahan dan kemiringan lereng dapat berubah dalam waktu yang relatif singkat.

b. Perhitungan Akurasi Peta Kerawanan Banjir DAS Jali Cokroyasan Kabupaten Purworejo

Peta kerawanan banjir akan dihitung akurasinya secara kualitatif dengan mencocokan dengan hasil in depth interview. Nilai akurasi bersifat kualitatif pada setiap satuan pemetaan ditambah dengan data historis kejadian banjir di daerah kajian. Hal tersebut akan menunjukan tingkat kemampuan penginderaan jauh dan sistem informasi geografis untuk pemodelan kerawanan banjir.

\section{HASIL DAN PEMBAHASAN}

Sebagian DAS Jali Cokroyasan Purworejo merupakan kawasan rawan banjir. Menurut Marfai (2011), kawasan rawan banjir merupakan kawasan yang berpotensi tinggi mengalami bencana banjir yang sesuai dengan karakteristik penyebab banjir. Karakteristik penyebab banjir di DAS Jali Cokroyasan Purworejo diidentifikasi melalui parameter intensitas hujan rata-rata tahunan, penggunaan lahan, kemiringan lereng, dan bentuklahan. Banjir yang terjadi di DAS Jali Cokroyasan Purworejo berdasarkan mekanisme terjadinya merupakan jenis banjir biasa (reguler) artinya banjir terjadi akibat jumlah limpasan sangat besar sehingga melampaui kapasitas pembuangan air yang ada (existing drainage), dalam hal ini banjir di DAS tersebut termasuk dalam banjir luapan.

DAS Jali Cokroyasan memiliki bentuk DAS memanjang dengan pola dendritik yang dominan pada wilayah hulu. Bentuk 
memanjang menurut Dam (1973) dalam Seyhan (1990) memiliki fungsi peubah-peubah DAS diantaranya debit banjir yang kurang atau waktu perjalanan yang lebih. Hal tersebut berarti debit banjir menuju outlet dan mencapai puncak membutuhkan waktu yang relatif lama, selain itu debit tertinggi tidak terlalu besar.

Berdasarkan hasil interpolasi dan perhitungan curah hujan rata-rata dalam 10 tahun, curah hujan paling tinggi yaitu $362-401 \mathrm{~mm}$ terjadi di wilayah hulu terutama di sebagian Kecamatan Bruno dan sebagian Kecamatan Gebang. Sebagian wilayah tengah memiliki curah hujan sedang hingga paling rendah yaitu 200-240,2 mm sedangkan wilayah hilir yaitu Kecamatan Ngombol dan Grabag memiliki curah hujan yang homogen yaitu 200-240,2 $\mathrm{mm}$. Variasi curah hujan dalam satu DAS tersebut disebabkan karena pengaruh topografi wilayah. Sebagian Kecamatan Bruno merupakan wilayah perbukitan dengan kemiringan lereng yang lebih besar daripada wilayah tengah dan hilir sehingga terpengaruh efek orografis. Efek tersebut menyebabkan pergerakan masa udara menuju ke tempat lebih tinggi lalu terjadi proses kondensasi kemudian terjadi hujan orografis sehingga curah hujan di wilayah hulu lebih tinggi. Hujan tersebut akan menjadi limpasan sehingga menaikkan debit sungai. Hujan tersebut menjadi pasokan air di hulu sungai yang selanjutnya mengalir menuju wilayah hilir.

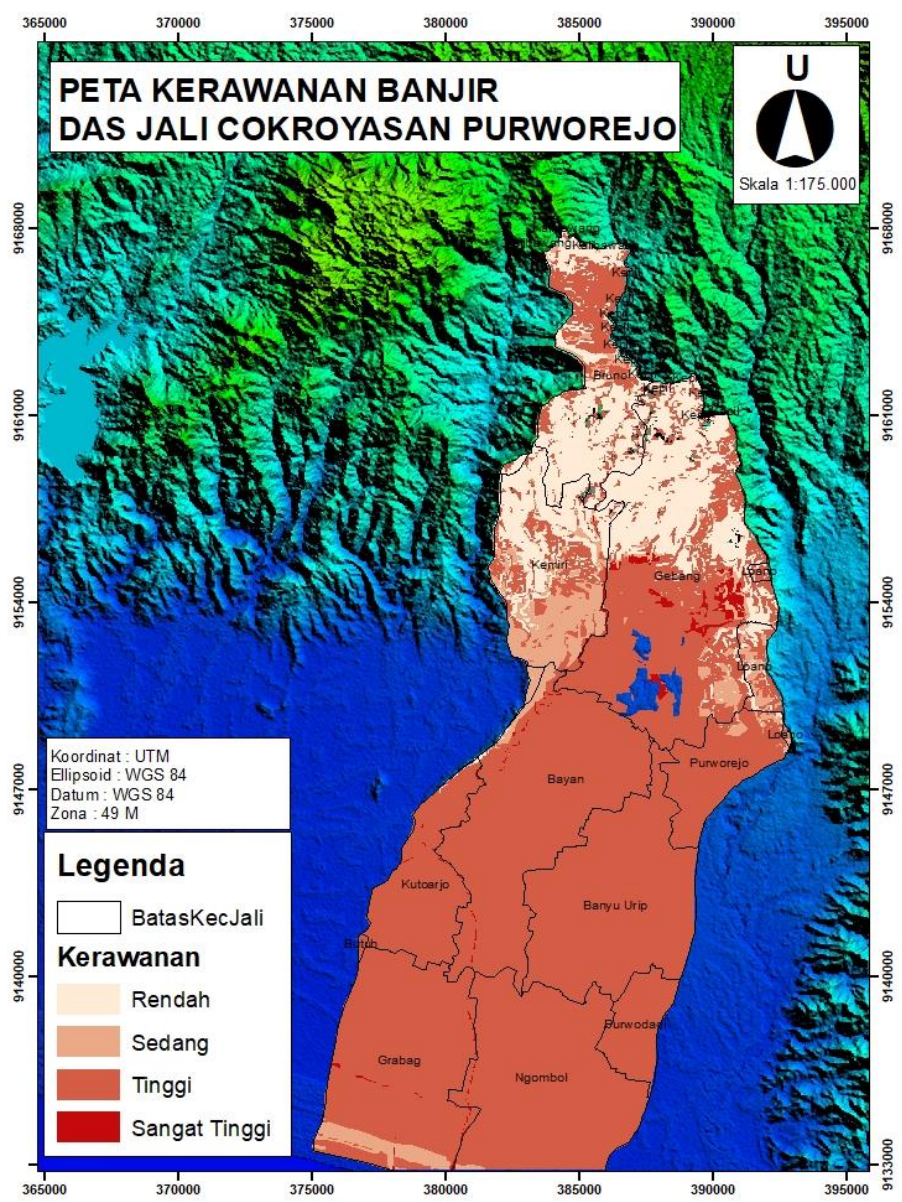

Gambar 11. Peta Kerawanan Banjir DAS Jali Cokroyasan Purworejo 
Peta kerawanan yang telah diperolah menunjukan bahwa pada DAS Jali yang berada di Kabupaten Purworejo memiliki tingkat kerawanan banjir yang cukup rawan. Hilir DAS yang mendekati outlet DAS menjadi area yang rawan terjadinya bencana banjir luapan. Hal tersebut disebabkan hilir DAS memiliki topografi yang landai. Sehingga ketika terjadi kiriman debit yang besar dari catchment area akan berakibat luapan debit air pada hilir DAS yang memiliki topografi relatif landai. Daerah disekitar sungai atau dataran banjir menjadi area yang paling rawan. Hal tersebut disebabkan karena pada area tersebut merupakan area yang paling dekat dengan pantai. Selain itu memiliki topografi landai dan tanah yang cenderung memiliki kapasitas infiltrasi yang rendah. Selain itu di daerah dataran banjir dan dataran aluvial terdeapat banyak permukiman yang menjadi basis tempat tinggal warga setempat. Sehingga akan sangat beresiko ketika terjadi banjir luapan. Kecamatan yang memiliki tingkat kerawanan cukup tinggi yaitu Kecamatan Grabag, Ngombol, Purwodadi, Buruh, Kutoarjo, Banyu Urip, Bayan, dan sebagian Kecamatan Gebang. Daerah yang tergolong tidak rawan banjir berada pada topografi yang curam dan memiliki relief berbukit hingga bergunung. Hal tersebut disesbabkan karena pada daerah tersebut memiliki tutupan lahan yang mampu menyerap air yang berasal dari hujan. Sehingga kapasitas infiltrasi menjadi lebih baik. Selain itu pada daerah tersebut merupakan daerah hulu yang memiliki banyak cabang sungai berorde kecil, sehingga limpasan permukaan dapat langsung masuk ke cabang-cabang sungai dan tidak berdampak pada permukaan.

Peristiwa banjir yang pernah terjadi banyak dialami di Kecamatan Grabag dan Ngombol. Berdasarkan hasil wawancara dengan sampel menyatakan bahwa banjir terjadi disebabkan karena luapan air akibat ketidakmampuan sungai untuk menampung debit yang mengalir. Selain itu banjir pernah terjadi akibat pertemuan dua anak sungai yang memiliki debit berbeda pada daerah hilir yang mendekati muara sehingga meluap tepat pada titik pertemuan dan menimbulkan dampak hingga ratusan meter baik ke arah hulu maupun ke arah hilir.

\section{KESIMPULAN}

Berdasarkan penelitian yang telah dilakukan dan hasil yang telah didapatkan menunjukan bahwa DAS Jali yang berada di Kabupaten Purworejo rawan terhadap bencana banjir. Kecamatan yang rawan terpapar bencana banjir merupakan kecamatan yang berada pada daerah hilir sungai. Terutama daerah yang berada di sekitar sungai yaitu daerah dataran banjir dan dataran aluvial. Parameter yang paling berpengaruh dalam pendugaan kerawanan banjir adalah paramater kemiringan lereng. Kemiringan lereng yang menunjukan topografi akan mempengaruhi infiltrasi dan limpasan permukaan.

Metode pembobotan Analytical Hierarchy Process yang diintegrasikan dengan metode Spatial Multi-Criteria Evaluation dapat digunakan untuk membantu dalam pendugaan kerawanan banjir menggunakan parameterparameter biofisik. Metode tersebut mengolah data dalam bentuk raster. Sehingga terjadi banyak perubahan ketika proses konversi data vektor ke raster atau sebaliknya. Kelemahan tersebut mempengaruhi hasil yang diperoleh. Sehingga akan lebih baik jika data yang didapatkan sejak dari awal merupakan data raster.

\section{UCAPAN TERIMA KASIH}

Penulisan makalah yang berjudul "Aplikasi Penginderaan Jauh dan SIG dengan Metode Analytical Hierarchy Process untuk Kajian Kerawanan Banjir di Das Jali Cokroyasan Purworejo" dapat terlaksana dengan baik berkat bantuan, dorongan, juga bimbingan dari berbagai pihak. Oleh karena itu penulis mengucapkan terima kasih yang sebesar-besarnya kepada

1. Sudaryatno selaku dosen pembimbing

2. Wirastuti Widyatmanti yang telah memberikan pengarahan dan bimbingan selama pembuatan makalah

3. Emilya Nurjani yang telah memberikan pengarahan dan bimbingan selama pembuatan makalah

4. Masyarakat sebagian Kabupaten Purworejo sebagai responden penelitian

\section{DAFTAR PUSTAKA}

Aronoff, S. 1989, Geographic Information System; A Management Perspective, WDL Publications, Ottawa.

Dinas Pertanian Peternakan Kelautan dan Perikanan. 2014. Data Curah Hujan, diakses 25 Februari 2018, 
http://dppkp.purworejokab.go.id/datacurah-hujan.

Heksantoro, R. 2017. Sungai Lereng Masih Meluap, 3 Desa di Purworejo Masih Tergenang, Detik News, diakses 11 Februari 2018, https://news.detik.com/berita-jawatengah/d-3752378/sungai-lereng-masihmeluap-3-desa-di-purworejo-masihtergenang.

Jankowski, P., dan Timothy N. 2009. Introduction to Spacial Decision Support System. Advanced Geographic Information Systems- Vol. II

Rai, K., dan Bhushan, N. 2004. Strategic Decision Making (Analythic Hierarchy Process). http://www.springer.com/9781-85233-756-8 diakses 15 Maret 2018.

Liliesand, Thomas M., Kiefer, dan Ralph W. 1979 terj. Dulbahri. Suharsono, Prapto. Hartono. Suharyadi (1990). Penginderaan Jauh dan Interpretasi Citra. Yogyakarta : Gadjah Mada University Press Lu Y. George dan David W. Wong, Jurnal Computer \& Geoscience, 1044-1055, July 2007.

Malingreau, J.1977. Apropose Land Cover/ Land use Classification and its use With remote Sensing Data In Indonesia. The Indonesian journal of Geography, No.33, Vol 7 Yogyakarta: Fakultas Geografi UGM.

Marfai, A. 2011. Modul Kuliah Pengelolaan Kebencanaan di Indonesia, Fakultas Geografi Universitas Gadjah Mada, Yogyakarta,

Prapto, S. 1999. Identifikasi Bentuklahan dan Interpretasi Citra untuk Geomorfologi, Puspics Fakultas Geografi Universitas
Gadjah Mada dan Bakosurtanal, Yogyakarta.

Rai, K., dan Bhushan, N. 2004. Strategic Decision Making (Analythic Hierarchy Process). http://www.springer.com/9781-85233-756-8 diakses 15 Maret 2018

Seyhan, E. 1990. Dasar-dasar Hidrologi. Gadjah Mada University Press. Yogyakarta. 